\title{
Sprawl e o modal de transporte motorizado: impactos na cidade de Londrina, PR
}

\author{
Sprawl and motorized modal transport: \\ impacts in the city of Londrina, PR
}

Mauríio Polidoro ${ }^{[a]}$, José Augusto de Lollo $0^{[b]}$, Mirian Vizintim Fernandes Barros ${ }^{[c]}$

[a] Geógrafo, Especialista em Análise Ambiental pela Universidade Estadual de Londrina (UEL), Mestre em Engenharia Urbana pela Universidade Federal de São Carlos (UFSCar), Doutorando em Geografia pela Universidade Federal do Paraná (UFPR), Curitiba, PR - Brasil, e-mail: polidoro@ufpr.br

[b] Engenheiro Geólogo, Livre Docente do Programa de Pós-Graduação em Engenharia Civil e Urbana, Universidade Estadual Paulista, Universidade Federal de São Carlos, São Carlos, SP - Brasil, e-mail: lolloja@dec.feis.unesp.br

[c] Geógrafa, Doutora em Geografia Física. Programa de Pós-Graduação em Geografia Dinâmica Espaço Ambiental, Universidade Estadual de Londrina, Londrina, PR - Brasil, e-mail: vizintim@uel.br

\section{Resumo}

Após cerca de 80 anos desde a construção do seu núcleo, representado hoje pela área central da cidade, Londrina, no interior do Estado do Paraná, configura-se como uma cidade nova, porém com características e tendências de políticas de planejamento que reproduzem os maus exemplos das cidades brasileiras. Com uma ocupação urbana em franca expansão, o crescimento de norte a sul do município agrega vazios urbanos e especulação imobiliária nos seus interstícios que delineia uma cidade longe da ideal, conforme pensada nos seus primórdios. Com um ar metropolitano, e ao mesmo tempo com aspectos interioranos, Londrina é marca de uma ocupação orientada por políticas excludentes e interesses imobiliários, fato que tem impactado o modo de vida da população e gerado impactos ambientais para todas as classes sociais. Esta pesquisa discute a forma de ocupação urbana de Londrina, caracterizada pelo fenômeno de sprawl e sua relação com o modo de expansão observado e as implicações do uso intensivo de automóveis. A opção pelo uso do automóvel em Londrina tem sido crescente e gerado congestionamentos no trânsito. Como consequência, tem-se a desapropriação constante de imóveis para alargamento de vias e, ao mesmo tempo, a presença de vazios urbanos e densidades diversas formando um espaço urbano desigual e dificultando um planejamento urbano eficiente.

Palavras-chave: Expansão urbana. Transporte urbano. Automóveis. Sprawl.

\begin{abstract}
After 80 years since the construction of its core, represented today by the central city area, Londrina, in the state of Parana, appears as a new city, but with features and trends of planning policies that reproduce the
\end{abstract}


bad examples of cities. With an urban settlement in frank expansion, north and south growth of the city add land speculation and urban voids in the interstices that outline a city far from ideal, as conceived in its beginning. With a metropolitan atmosphere and at the same time countryside aspects, Londrina is a brand of exclusive occupation policy-driven and real estate interests, a fact that has impacted the livelihood of the population and generated environmental impacts for all social classes. This research discusses the kind of occupation in Londrina, characterized by the phenomenon of sprawl and its relation to the mode of expansion observed and the implications of intensive use of cars. The choice of car use in Londrina has been growing and generated bottlenecks in traffic. As a consequence there is the constant expropriation of property for widening of roads and at the same time, the presence of various densities and urban voids forming an uneven urban space and hindering an efficient urban planning.

Keywords: Urban expansion. Urban transport. Vehicles. Sprawl.

\section{Introdução}

Nesta nova década do novo século, o fenômeno da urbanização no Brasil tomou uma nova frente com a consolidação parcial das áreas ocupadas em detrimento das áreas rurais. Essa nova configuração, ligada intimamente às novas relações sociais, tem produzido uma mutação no espaço, uma nova realidade que surge no processo, lugares que não são nem rurais e tampouco urbanos (CHOAY, 1999).

A nova realidade, aliada a políticas públicas de investimentos maciços em infraestruturas, como rodovias e megaeixos de circulação em determinadas regiões, tem construído e incentivado o surgimento de novas cidades bem como a dispersão de outras já consolidadas, onde os limites político-administrativos dos municípios vão desaparecendo e cedendo lugar a uma paisagem nebulosa caracterizada principalmente por densas ocupações no entorno de redes de escoamento.

Essa realidade, quando observada na escala regional, mostra uma ocupação contígua conectada por autovias com cidades lineares e dispersas, semeadas por fios condutores de transportes; e quando observada na escala intraurbana, mostra ocupações longe do centro consolidado com inúmeros vazios urbanos e um intenso processo de periferização em diversas grandezas sociais.

No espaço intraurbano, os incentivos para a aquisição do meio de transporte individual, por meio de marketing ou da redução de impostos, fazem com que parte da população veja o automóvel como a melhor escolha para locomoção na cidade, inclusive por permitir a escolha do lugar onde morar, tendo em vista que este lugar pode estar isolado das localidades concentradoras dos serviços e lazer.

Essa sistemática conduz a impactos significantes no meio intraurbano e no plano regional. Tem-se, no primeiro, a ocupação cada vez mais dispersa de residências e o automóvel é o principal meio de locomoção em detrimento ao transporte público coletivo, renegado dos investimentos públicos. No nível regional, a concentração das ocupações em áreas limítrofes tem constituído áreas metropolitanas confinantes, com ocupação de residências, comércios e indústrias, a qual cria uma lógica complexa tanto no sentido da forma urbana quanto de seu governo.

Dessa forma, a influência da escolha do transporte individual na ocupação das cidades e os impactos sociais e ambientais merecem destaque perante a realidade brasileira, já que os esforços para a aquisição de veículos é cada vez mais intenso. Este artigo aborda a questão da escolha do automóvel como modo de transporte na cidade de Londrina, explicitando os impactos que essa preferência tem causado e suas implicações no meio urbano.

\section{Sprawl urbano: conceitos e características}

O conceito de sprawl urbano tem sido difundido pelos pesquisadores norte-americanos, caracterizando e justificando as formas de ocupação de muitas das cidades daquele país para embasar proposições mitigadoras dos inúmeros impactos socioambientais decorrentes do fenômeno, como a política do smart growth ("crescimento inteligente") aplicada em Portland, Oregon, a partir da década de 
1970, sendo referência mundial no âmbito de planejamento urbano.

Para Burchell (2003, p. 2), sprawl é:

low-density, leapfrog development that is characterized by unlimited outward extension. In other words, sprawl is significant residential or nonresidential development in a relatively pristine setting. In nearly every instance, this development is low density, it has leapt over other development to become established in an outlying area, and its very location indicates that it is unbounded.

Este é, então, caracterizado pela dispersão da ocupação urbana, que, de forma rápida, atinge áreas rurais e é qualificado principalmente em função da baixa densidade demográfica dessas áreas que se expandem para além do centro consolidado.

Johnson (2001) complementa que o fenômeno do sprawl ocorre além do centro de serviços e oferta de empregos, separando, assim, o lugar onde as pessoas compram e trabalham e, até mesmo, onde estudam do local onde moram. Alguns dos principais indicadores desse fenômeno são: a geração de grandes vazios urbanos, a alta descentralização das terras pertencentes ao Poder Público e a falta e/ou incapacidade deste em controlar o valor da terra na cobrança fiscal, fato que impossibilita a justiça tributária e, consequentemente, acirra as desigualdades sociais, já que a cobrança dos impostos não é fiel à situação econômica e espacial da população.

É consenso que o sprawl urbano traz mais malefícios que benefícios ao espaço urbano. Dentre os aspectos negativos, Burchell (1998) destaca os seguintes:

1) Urbanização dispersa: criação de loteamentos em lugares distantes do centro consolidado, criando inúmeros vazios urbanos.

2) Desenvolvimento de áreas com baixa densidade demográfica: ocorre principalmente nas regiões com casas individuais (singles) ou naquelas áreas com renda mais alta, deixando grande parte da infraestrutura instalada obsoleta ou subutilizada; pode, ainda, ser caracterizada pelas localidades com uso apenas de comércio.

3) Área de expansão urbana: a delimitação físico-territorial desordenada das áreas de expansão urbana diminui a área agrícola e incita a valorização da terra no processo de transformação rural-urbano.

O sprawl urbano nas cidades brasileiras pode ser caracterizado tanto pela criação dos novos loteamentos pela prefeitura ou por loteadoras públicas e privadas para a construção de conjuntos habitacionais, ou pela criação de subúrbios de alta renda, como é o caso dos condomínios horizontais, todos distantes do centro consolidado.

Esse modelo de urbanização distante do centro consolidado, além de dividir as classes sociais, tem gerado algumas características específicas de ocupação. Os conjuntos habitacionais ou as áreas de ocupação irregulares, assim como em diversas cidades estadunidenses, conforme observado em Carbonell e Yaro (2005), têm se concentrado no entorno ou em localidades próximas a anéis de integração ${ }^{1}$.

Os impactos desse modelo de ocupação no meio ambiente ocorrem tanto para os ricos como para os pobres; entretanto, os efeitos sobre a população com menor renda são mais marcantes, já que estes são afastados do centro consolidado retentor do comércio, dos serviços e das oportunidades de empregos. Provoca, além da segregação socioespacial, a restrição no acesso à infraestrutura, como o transporte público, essencial para o deslocamento diário dessa população até seus locais de trabalho, os quais, muitas vezes, estão localizados nas áreas centrais.

Para a população de maior renda, apesar de possuírem automóveis e o transporte entre localidades ser mais facilitado, já que comumente as ruas e avenidas são mais bem estruturadas, ocorre o congestionamento do sistema viário, além da alta emissão de $\mathrm{CO}_{2}$, prejudicando diretamente a qualidade ambiental das cidades e a saúde da população.

Outro fator impactante na regulação do uso do solo e densidade demográfica refere-se àquele uso estritamente comercial, de baixa densidade, usualmente caracterizado por regiões que concentram

1 Este fenômeno de urbanização no entorno de anéis de integração e/ou rodovias também é observado em pequenos municípios. 
"corredores de comércio", geralmente no entorno de rodovias dentro do perímetro urbano ou em ruas especializadas em serviços. Isso porque, para acessar tais serviços, a população precisa locomover-se por meio de automóveis ou transporte público, como indica Ojima e Hogan (2008a, p. 4):

[...] os aspectos que são considerados como efeitos negativos nos modelos de urbanização dispersa está o uso intensivo de transporte automotivo, sobretudo o de uso individual e, embora essa característica possa ser atribuída tanto como causa e como consequência, a verdade é que quanto menor a densidade populacional, tende a ser maior o deslocamento espacial da população para as atividades cotidianas.

Limonad (2007), na tentativa de compreender o motivo pelo qual as diferentes classes sociais tomam rumo a localidades periurbanas, mostra uma relação dicotômica no processo: de um lado, o segmento social que retém a força do trabalho, acompanha a relocação industrial, geralmente na periferia urbana; e de outro, as classes mais abastadas que buscam, longe do centro, locais mais tranquilos para viver.

Essa forma de ocupação pelas diferentes classes sociais ao longo das franjas urbanas é caracterizada por áreas periféricas de baixa densidade e é um fenômeno mundial, com exceção de algumas aglomerações nos Estados Unidos (LIMONAD, 2007).

Neste artigo, apresentamos o sprawl urbano em Londrina como uma combinação de: ocupação dispersa no solo em virtude de novos projetos urbanos, conexões dessas áreas por estradas e avenidas em que se desenvolveram corredores comerciais, a falta de investimentos em transporte público, a fim de atender estas novas áreas periurbanas, e o uso intenso de carros como o modo de transporte principal.

Em Londrina, a expansão urbana se caracteriza também pela ocupação de diferentes classes sociais nos subúrbios; no entanto, observa-se que as regiões ocupadas por moradores de baixa renda têm densidades populacionais próximas às encontradas no centro consolidado, como é o caso no norte da região da cidade.

Comum a todas essas situações, nos interstícios desse modo de ocupação, os vazios urbanos, caracterizados por áreas não loteadas, ocorrem frequentemente e ficam principalmente em domínio dos agentes imobiliários; e apesar de estarem localizados em áreas com infraestrutura completa, são utilizados para especulação e valorização da terra.

Quando essas regiões são localizadas nos limites do perímetro urbano, os proprietários das terras aguardam sua valorização para propósitos de especulação, ocasionando um tipo de desenvolvimento não contíguo (AURAND, 2007), já que muitas vezes determinadas áreas são destinadas à construção de condomínios fechados, isolados das áreas com ocupação consolidada, gerando terras inabitadas no seu entorno.

Naquelas com baixa densidade, que são caracterizadas principalmente por edifícios e residências e condomínios para pessoas sozinhas (singles), casais ou pequenas famílias (casais com apenas um ou dois filhos, por exemplo), são usualmente afastados dos locais onde estão concentrados os comércios como os shopping centers, por exemplo - (AURAND, 2007); porém, essa é a classe social que mais utiliza tais serviços.

Além das áreas de baixa densidade, o crescimento nos limites da expansão urbana também é efeito do sprawl, caracterizando um fenômeno de periurbanização que se refere à ampliação da mancha urbana em direção às suas periferias (OJIMA; HOGAN, 2008b), ou seja, a ocupação do solo passa a se expandir para as franjas urbanas, diminuindo assim, as áreas agrícolas, o que prejudica, muitas vezes, áreas de preservação ambiental onde é praticamente impossível identificar se a região é urbana ou rural. Essas áreas,

[...] que antes era tradicionalmente ligada a atividades agrícolas está sendo agora utilizada para atividades industriais (principalmente pela agroindústria), ou ainda por ocupações residenciais de baixa densidade. Assim, as fronteiras que antes dividiam com relativo grau de certeza as áreas urbanas erurais estão cada vez menos visíveis. Neste sentido, o debate sobre os critérios que definem áreas urbanas e áreas rurais se acentua na medida em que tais fronteiras são diluídas por novas formas de uso e ocupação em áreas peri-urbanas (OJIMA; HOGAN, 2008b, p. 6).

Em áreas metropolitanas, o avanço da ocupação em áreas limítrofes a outros municípios, por exemplo, pode provocar grandes impactos se não forem utilizados os instrumentos de planejamento urbano, como o zoneamento, de forma articulada. 
Nessas áreas limítrofes geralmente se concentram tanto indústrias como ocupações residenciais, geralmente de baixa renda, e, na maioria das vezes, não se respeita os instrumentos de política urbana do município vizinho, incitando grandes impactos ambientais e, principalmente, de vizinhança (OJIMA; HOGAN, 2008b).

Enquanto tais regiões concentram usos residenciais, industriais e comerciais em localidades vizinhas a outros municípios, a fragmentação urbana no território provoca

[...] ilhas de diversos tamanhos e localizações, definindo cheios e vazios. Por sua vez, o avanço contínuo da mancha urbana sobre as bordas da cidade denota que a dispersão parece não ter barreiras, sejam físicas ou sociais. Nesse caso, as forças são predominantemente de distensão, com baixa densidade, pontuando os conflitos entre a acessibilidade e o uso e a ocupação da terra urbana (RIBEIRO; SILVEIRA, 2009, p. 1).

Todos esses aspectos, aliados à forma de expansão urbana ligada ao automóvel, provocada principalmente pela desintegração das políticas urbanas, levam a um conjunto sistêmico de problemas para as cidades. Este item será discutido a seguir.

\section{A escolha modal do transporte motorizado e suas implicações}

Jong e Rouwette (2009) trazem a discussão dos impactos provocados pela escolha do uso do automóvel como indutor da expansão urbana. A densidade, por exemplo, acaba gerando atividades dispersas quando em níveis baixos e médios.

Além disso, o uso do solo, usualmente homogêneo e segregado, utiliza-se de índices e zonas restritivas que acabam concentrando, em determinadas áreas, serviços específicos que exigem o uso do automóvel para locomoção.

A escala é outro fator de impacto resultante do uso intenso do automóvel, já que a cidade é vislumbrada dentro do carro. Esse fator está também ligado ao de projeto de ruas e conectividade. Os projetos geralmente são guiados pela circulação dos automóveis e muitos imóveis são desapropriados para ceder lugar ao alargamento de vias. Neste sentido, a caminhada e o uso de bicicletas no transporte são comprometidos, já que os veículos têm preferência.

Além disso, a criação de rotatórias, vias hierarquizadas e ruas sem saídas atrapalham os pedestres e transportes com tração humana. Esse modelo de planejamento também inibe o transporte público de acessar determinadas regiões.

Por fim, o uso crescente de áreas para a construção de vias, ou até mesmo de shoppings e condomínios fechados, diminui o espaço dedicado a atividades de lazer público, tendo em vista que o particular é cada vez mais presente na vida urbana.

Todos esses níveis de impactos estão também ligados aos problemas de estruturação institucional, considerando-se que, muitas vezes, os departamentos das prefeituras não são integrados e criam políticas setorizadas e desvinculadas.

Além disso, os projetos de baixa densidade produzidos para famílias singles criam uma paisagem urbana dispersa, induzem a ocupação urbana no sentido linear, especialmente em cidades pequenas, produzidas por meio da instalação de grandes empreendimentos ao longo de rodovias. Morris (2005) aponta quatro consequências do sprawl e sua relação com o uso do carro.

1) Falta de padrões de uso múltiplo: há falta de escolas, locais de trabalho, cafés, restaurantes, escritórios, edifícios públicos e residências a uma curta distância, em razão da rigidez do zoneamento.

2) Dependência do automóvel: como as funções básicas da vida na cidade estão espalhadas, o automóvel é o modo mais viável de transporte, considerando-se a precariedade do transporte público. Além disso, novos subúrbios e condomínios fechados verticais são projetados para acomodar os números crescentes de espaços de estacionamento. 0 deslocamento a pé não é entendido como uma forma segura de ir a qualquer lugar, reduzindo calçadas e interação social. Isso se agrava em cidades com índices de violência urbana.

3) Congestionamentos: as divisões hierárquicas de vias urbanas, que geralmente são ligadas a uma via arterial, saturam-se em horários de pico. A falta de rotas alternativas e desenho geométrico irregular das ruas prejudicam a locomoção de pedestres e automóveis. 
4) Transporte público inadequado: o transporte de massa é insuficiente, mal planejado (em geral, ou inicialmente, não incluído no planejamento do uso da terra), com exceção do transporte (geralmente privado, para viagens intermunicipais) ao longo das estradas principais (avenidas e rodovias).

Essas são as principais características da expansão urbana, causadas pelo uso do carro como um meio de transporte principal nas cidades brasileiras. Os pedestres são deixados de fora como os principais interessados no planejamento das cidades, dando espaço aos automóveis privados.

\section{Sprawl urbano em Londrina}

A gênese da ocupação urbana da cidade de Londrina deu-se, sobretudo, em virtude do potencial econômico gerado por sua localização estratégica, sendo a formação do seu espaço intraurbano (representado pelo centro principal) em razão das ações conjuntas de comerciantes da ACL (Associação dos Comerciantes de Londrina, hoje incluído "Indústria" e denominado ACIL).
Citando Tomazzi (2000), em relação à ideologia de "pioneiros" que perdurava na classe dominante regional (formada principalmente por estrangeiros) na década de 1930, Ribeiro (2004) afirma que a ideia comum daquele grupo era a busca do "desenvolvimento de Londrina", com o objetivo principal de enriquecer a cidade, apesar de conflitos com o governo estadual.

Em busca desse "desenvolvimento", o grupo intensificou o trabalho para a transformação de Londrina em uma cidade industrial, especialmente após a crise no campo, provocada pela geada de 1975. É a partir desse momento, com as oportunidades que o meio urbano oferecia, que a massa rural migrou para a cidade, a qual passou a concentrar diversos segmentos de comércio, constituindo-se então, o núcleo urbano de Londrina.

A partir da década de 1950, a ocupação no entorno do centro expandiu-se para regiões onde bairros mais populares foram se concentrando. Mais acentuado, por volta da década de 1960, observa-se a constituição da ocupação em regiões esparsas, caracterizando, a partir dessa época, o fenômeno de sprawl, apesar de alguns interstícios serem urbanizados posteriormente, embora com grandes vazios urbanos (Figura 1).

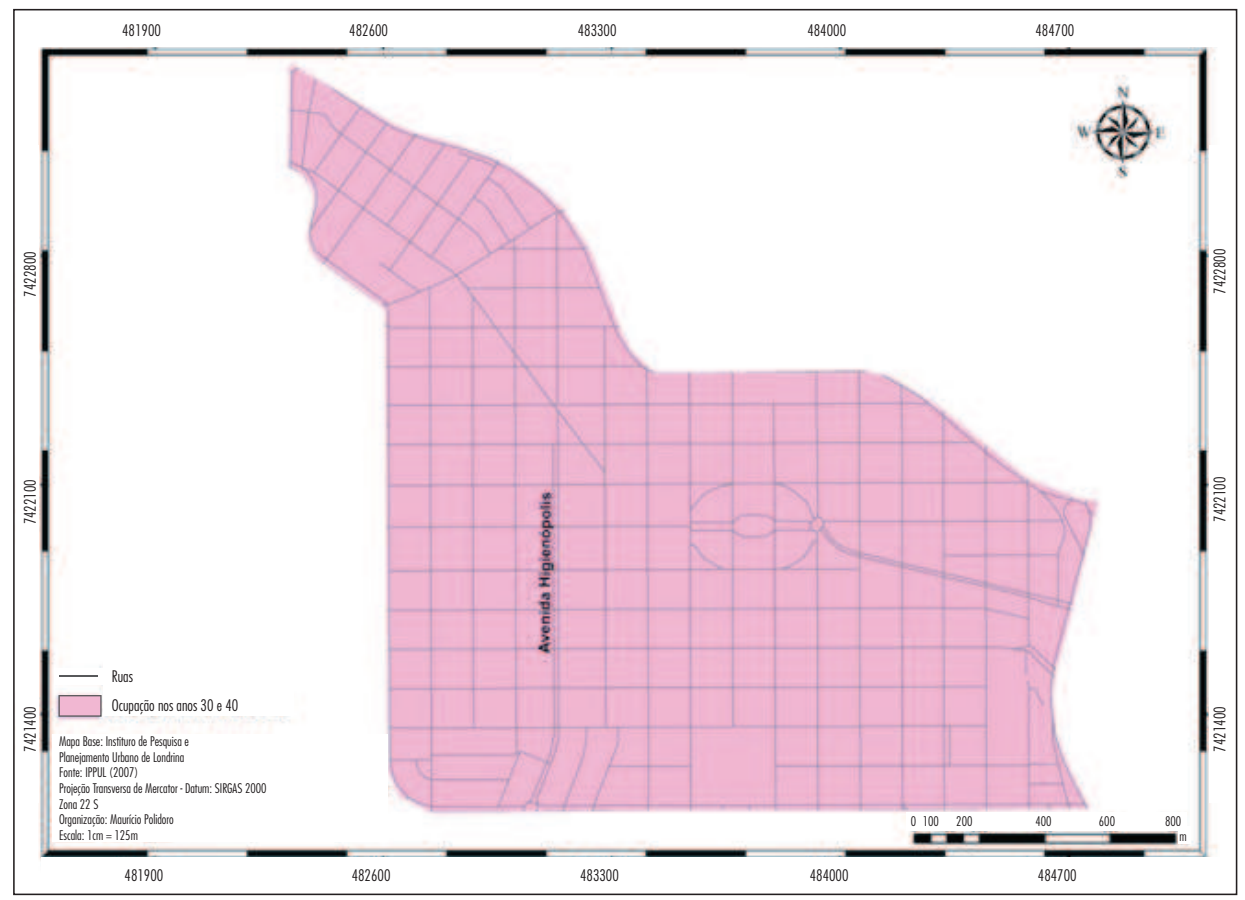

Figura 1 - Londrina nas décadas de 1930 e 1940 Fonte: POLIDORO, 2010. 
As ocupações começaram a se tornar mais esparsas na década de 1960 (Figura 2), e não acompanhadas da oferta de transporte urbano; inicia-se, então, o fenômeno de sprawl na cidade. A ocorrência desse fenômeno neste período também se deu em inúmeras metrópoles dos Estados Unidos, conforme aponta Carbonell e Yaro (2005), e diversas cidades brasileiras, sobretudo em razão do modelo político e econômico vigente na época, especialmente no governo de Juscelino Kubitschek, com o "Plano de Metas".

Razente (1983) afirma que a expansão urbana acentuada na década de 1960 decorre da implantação do Lago Igapó, da construção do aeroporto e da rodovia BR-369, que auxiliaram a ocupação dispersa tanto em virtude da especulação imobiliária que o lago proporcionou quanto da rodovia, pela construção de indústrias e casas populares no seu entorno.

Foi nessa mesma década que Londrina construiu, com a participação de consultores de São Paulo, seu Plano Diretor de Desenvolvimento Urbano de caráter tecnocrático, com grande ênfase no sistema

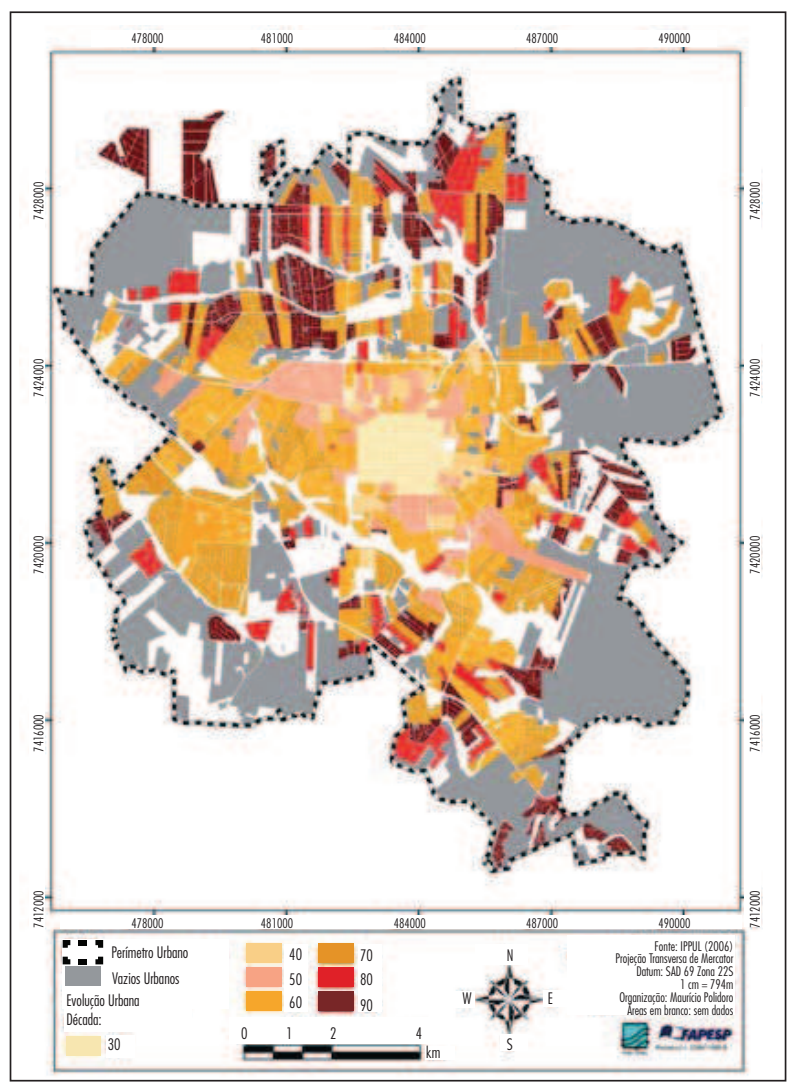

Figura 2 - Expansão urbana de Londrina Fonte: POLIDORO, 2010. viário e zoneamento, dando início a um processo de grande incitação de ocupação em sprawl no sentido centro-bairro (CASARIL, 2009).

Tendo como fomento a instalação de comércio no eixo centro-norte que acirrou o processo de ocupação em forma de sprawl, e, mais futuramente, na região sudoeste, sobretudo após a instalação do Shopping Catuaí, no fim da década de 1980, e das universidades particulares.

Esses acontecimentos incitaram o surgimento de inúmeros loteamentos de condomínios fechados e, consequentemente, vazios urbanos no percurso centro-sul, com disposição de infraestrutura completa, porém subutilizada e, muitas vezes, obsoleta. A demanda de moradias cresceu, e as casas do tipo single foram cada vez mais procuradas (CASARIL, 2009).

A partir da década de 1970, o crescimento populacional se dá de forma intensa seguindo a tendência nacional. Com a intensificação do processo do êxodo rural a população rural decresce de $42,60 \%$ em 1960 para $11,52 \%$ em 1980 e atingindo patamares de apenas 6\% em 1991 (Tabela 1).

É possível afirmar, a partir dos dados demográficos da Tabela 1, que da década de 1960 até 1990 a população urbana teve crescimento aproximado de 100 mil habitantes por década. Em 1970, a população rural ainda crescia positivamente, porém de forma desacelerada.

No início dos anos 1980, a intensa mecanização do campo e as mudanças nos padrões de exploração agrícola - como a substituição dos cafezais por lavoura mecanizada - contribuíram para a forte migração para a área urbana, que levou à ocupação da região norte, conhecida popularmente hoje como região dos "cinco conjuntos". A partir desse período, a dinâmica urbana iniciou um processo de transformação.

Esse processo tem se intensificado com o gradativo aumento da população urbana entre 2000 e 2010. A população rural, apesar de ter sofrido queda no número de habitantes de acordo com o mais recente Censo do IBGE, teve seu percentual de migração reduzido, porém em curso.

Em 1980, a verticalização tomou novas frontes, e o incremento da construção civil foi intenso, apesar da crise econômica no contexto nacional (PASSOS, 2007). Estabelece-se, a partir deste momento, o início de uma configuração urbana desigual: o centro passa a consolidar a maior densidade demográfica juntamente com os conjuntos habitacionais da região 
Tabela 1 - Dados demográficos de Londrina

\begin{tabular}{|c|c|c|c|c|c|c|c|}
\hline \multirow{3}{*}{ Ano } & \multicolumn{6}{|c|}{ População residente } & \multirow{3}{*}{$\begin{array}{l}\text { Taxa de } \\
\text { crescimento } \\
\text { geométrico }\end{array}$} \\
\hline & \multicolumn{2}{|c|}{ Urbana } & \multicolumn{2}{|c|}{ Rural } & \multicolumn{2}{|c|}{ Total } & \\
\hline & Número & $\%$ & Número & $\%$ & Número & $\%$ & \\
\hline 1950 & 34.230 & 47,93 & 37.182 & 52,07 & 71.412 & 100,00 & . \\
\hline 1960 & 77.382 & 57,40 & 57.439 & 42,60 & 134.821 & 100,00 & 6,60 \\
\hline 1970 & 163.528 & 71,69 & 64.573 & 28,31 & 228.101 & 100,00 & 5,40 \\
\hline 1980 & 266.940 & 88,48 & 34.771 & 11,52 & 301.711 & 100,00 & 2,82 \\
\hline 1991 & 366.676 & 94,00 & 23.424 & 6,00 & 390.100 & 100,00 & 2,36 \\
\hline 1996 & (2) 396.121 & 96,19 & (2) 15.000679 & 3,81 & (2) 411.000800 & 100,00 & \\
\hline 2000 & 433.369 & 96,94 & 13.696 & 3,06 & 447.065 & 100,00 & 2,02 \\
\hline 2010 & 493.520 & 97,40 & 13.181 & 2,60 & 506.701 & 100,00 & - \\
\hline
\end{tabular}

Fonte: IBGE - Censos Demográficos 1950, 1960, 1970, 1980, 1991, 2000 e 2010; Contagem da População 1996 (IBGE, 2010).

Notas: (1) Já subtráida a população de Tamarana, que era distrito do Município de Londrina e foi desmembrado dele, por meio da Lei Estadual n. 11.224, de 13/12/1995. (2) Organização dos dados: PML/SEPLAN/Gerência de Pesquisas e Informações.

Norte, em detrimento de inúmeras regiões sem ocupação nenhuma ou com densidade baixa/média, contíguas à área central, dotadas de infraestrutura, constituindo-se vazios urbanos nos interstícios (Figura 3).

As ocupações irregulares que foram se localizando nas periferias da cidade, como na região sul (declive acentuado) e áreas de preservação permanente na região leste e norte, foram delineando uma cidade de densidade desigual. Dessa forma, a infraestrutura instalada nos bairros contíguos à área central passou a abastecer regiões com pouca demanda, em virtude do baixo número de habitantes ou até mesmo nenhum (grandes vazios urbanos). Aqueles localizados nas regiões periféricas de alta densidade populacional ficaram com infraestrutura incompleta ou inexistente.

\section{Impactos do uso do automóvel em Londrina}

Apesar do "segundo plano" nas discussões do modo de vida encontrado nas grandes áreas urbanas, Ojima e Hogan (2008a, p. 2) apontam que o

setor de transportes será um dos principais componentes no aumento das emissões diretas de

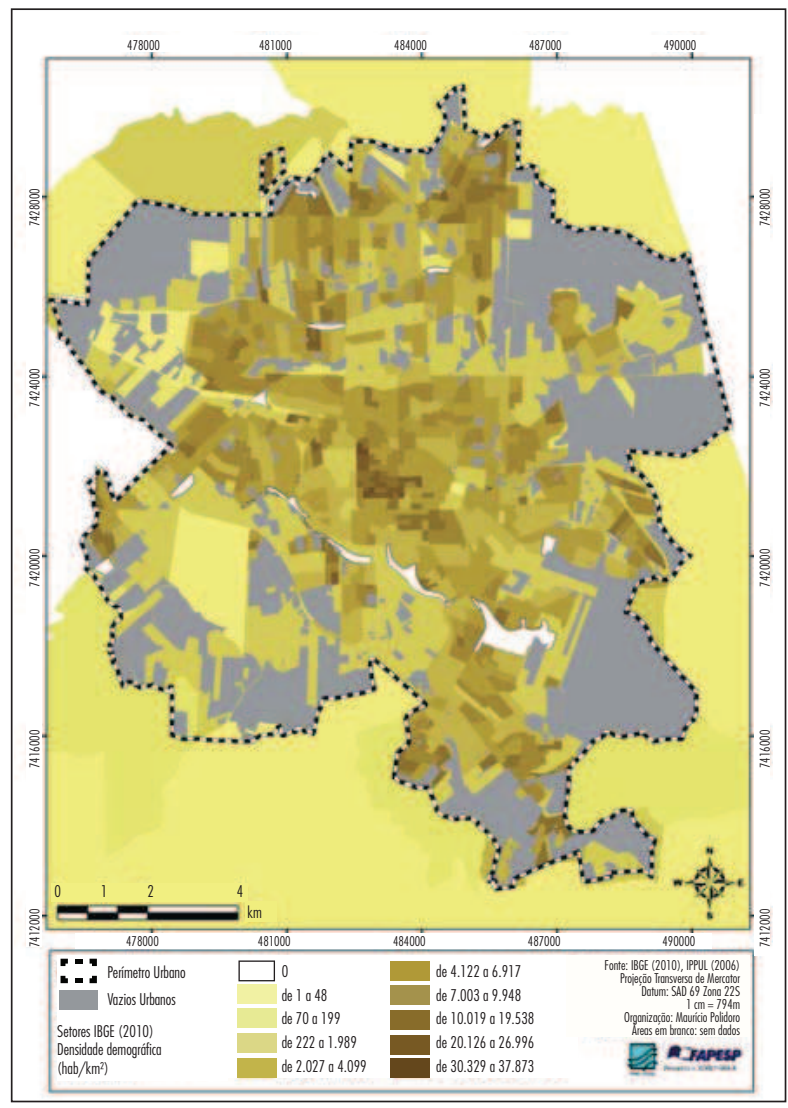

Figura 3 - Densidade demográfica e os vazios urbanos de Londrina Fonte: POLIDORO, 2010. 
GEE, serão nas áreas urbanas que estes processos ocorrerão com maior evidência. Segundo estimativas elaboradas por pesquisadores da COPPE/ UFRJ, o consumo energético, dentro do qual se encontra o consumo de combustíveis fósseis, contribui com cerca de $75 \%$ das emissões no município de São Paulo, seguido por $23 \%$ provenientes da disposição final de resíduos sólidos.

Ou seja, as discussões do desmatamento e dos resíduos gerados nas diversas cidades são de suma importância para a agenda ambiental do novo século, porém, algumas prioridades devem ser levantadas na discussão, como a solução dos congestionamentos, a viabilidade de investimento nas ciclovias e os limitantes para a construção de um novo modo de vida no meio urbano.

Em Londrina, observa-se que a questão do uso do automóvel é uma das maiores consequências do fenômeno do sprawl, trazendo consigo problemas de poluição ambiental e segregação socioespacial. Sobre os impactos dos gases de efeito estufa em Londrina, Lisboa e Barros (2010, p. 14) apontam:

Tendo em conta que cada litro de combustível libera 2,3 $\mathrm{kg}$ de $\mathrm{CO}_{2}$, e que a frota total de veículos de Londrina em 2004 era de 183.952, chega-se a $347.779,651 \mathrm{t}$ de $\mathrm{CO}_{2}$ emitidos neste período. Como 1,8 t de $\mathrm{CO}_{2}$ emitido serão absorvidos por cada hectare de área verde, e Londrina possui 3.323 ha de áreas verdes, têm-se 5981,4 t para absorção de $\mathrm{CO}_{2}$ em Londrina. Subtraindo os valores de toneladas emitidas e toneladas absorvidas, chega-se a um total de $341.798,251$ t de $\mathrm{CO}_{2}$.
As autoras afirmam ainda, utilizando a pegada ecológica como um indicador da sustentabilidade urbana, que

O consumo de combustíveis fósseis influenciou no aumento da pegada, devido à existência do grande número de veículos individuais, o que demonstra a necessidade de investimento em transporte público de qualidade pelos governantes. Uma opção é a ciclovia que pode se adequar bem a áreas com baixas declividades (LISBOA; BARROS, 2010, p. 22).

Apesar do intento de alguns programas socioeducativos na área do trânsito e meio ambiente (como a Semana do Trânsito, ocorrida anualmente promovida pelo Instituto de Pesquisa e Planejamento Urbano de Londrina - IPPUL e os encontros com a temática ambiental promovido pela Secretaria do Meio Ambiente - SEMA) dados do Denatran (Tabela 2) demonstram um aumento brusco na escolha dos automóveis como meio de locomoção no município. As categorias de Automóveis e de Motocicleta somavam em 2005 mais de 84\%, do total de veículos em Londrina. E o ônibus, principal meio de transporte coletivo, apresenta-se em número insignificante, considerando-se a população de 506.701 habitantes (IBGE, 2010).

Incentivos à indústria automotora pelo governo federal e os programas de redução de IPI e outros impostos, além de facilidades de financiamento, intensificaram, a partir do governo Lula, o aumento do número de automóveis e a consolidação deste meio enquanto status social. A nova classe média

Tabela 2 - Evolução do tipo de transporte automotivo utilizado

\begin{tabular}{|c|c|c|c|c|c|c|c|c|c|c|}
\hline \multirow{2}{*}{ TIPO } & \multicolumn{9}{|c|}{ ANO } & \multirow{2}{*}{$\begin{array}{l}\text { Tx. cresc } \\
\text { (aa\%) }\end{array}$} \\
\hline & 1998 & 1999 & 2000 & 2001 & 2002 & 2003 & 2004 & 2005 & 2011 & \\
\hline Automóvel & 99.300 & 103.718 & 101.315 & 106.066 & 110.315 & 116.968 & 123.695 & 131.264 & 184.842 & $3,62 \%$ \\
\hline Camioneta & 13.100 & 13.921 & 14.928 & 15.040 & 14.171 & 13.268 & 13.112 & 20.822 & 31.100 & $5,85 \%$ \\
\hline Caminhão & 6.216 & 6.398 & 5.987 & 6.310 & 6436 & 6.677 & 6.850 & 7.093 & 10.776 & $1,61 \%$ \\
\hline Motocicleta & 21.111 & 21.486 & 20.457 & 22.143 & 23.562 & 26.491 & 29.321 & 32.180 & 57.811 & $5,59 \%$ \\
\hline Ônibus & 1.516 & 1.494 & 1.444 & 1.472 & 1.389 & 1.429 & 1.450 & 1.505 & 1.988 & $0,45 \%$ \\
\hline
\end{tabular}

Fonte: DENATRAN, 2012. 
- a Classe $C$ - segue a cultura da "antiga" classe média, delineando um cenário preocupante em função dos crescentes indicadores de consumo, não apenas do automóvel.

Os investimentos decrescentes em transporte público, especialmente em áreas onde vive a camada mais pobre da população (principalmente nas periferias), como visto na Figura 4, caracterizam e intensificam o espaço urbano desigual e as possibilidades para que a população se desloque na cidade, por exemplo, para ir para centros comerciais e parques públicos (concentrada na região sul, perto das universidades). A disponibilidade de transporte público é geralmente localizada no centro e nas regiões vizinhas. Para o extremo sul e norte, onde há uma maior concentração de famílias de baixa renda, a frequência de transporte público é irregular ou semirregular (longo tempo de espera para os ônibus).

A Figura 4 mostra claramente que a maioria das regiões situadas em áreas de expansão urbana e

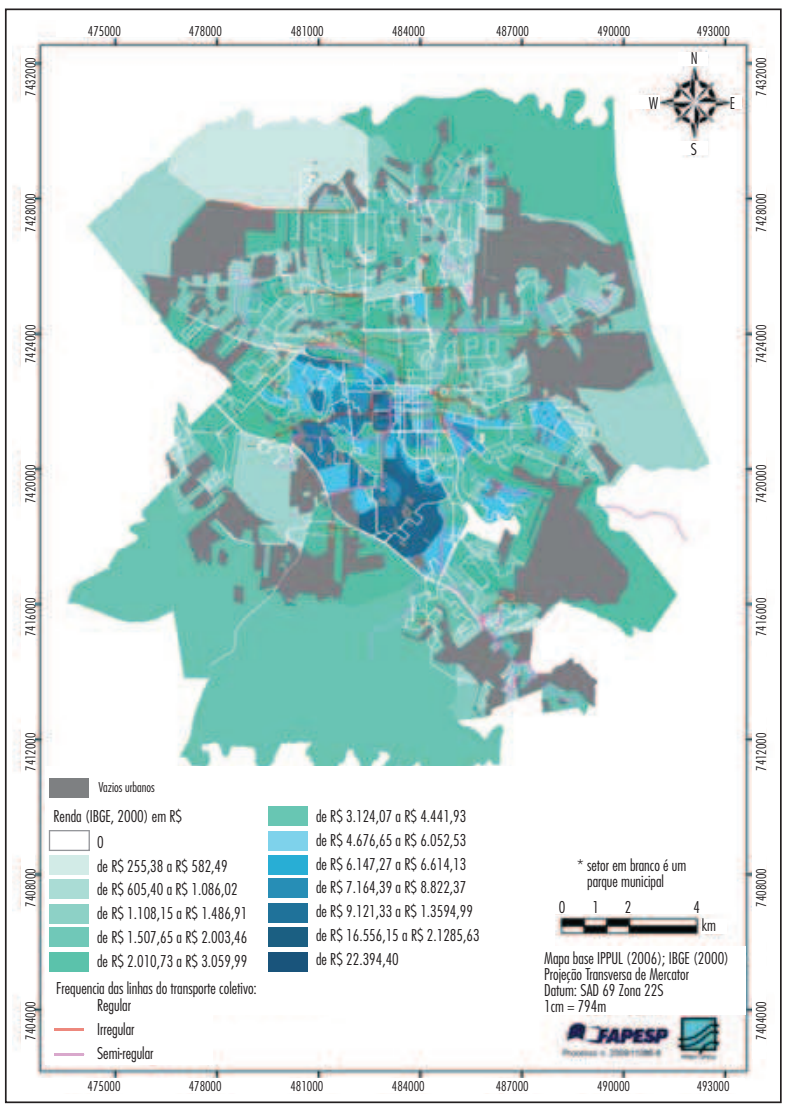

Figura 4 - Rendimento nominal médio e frequência do transporte coletivo em Londrina

Fonte: Dados da pesquisa. instaladas após a década de 1990 concentram o maior percentual de vazios urbanos e também a população de baixa renda, delineando um cenário de segregação social intensa. A população de maior renda e os usuários de carros particulares vivem perto de áreas que têm frequência de transporte público regular, apesar de não usarem tal modo de transporte para comutar.

Essa situação é semelhante em outras cidades brasileiras de porte médio como Londrina. A Figura 5 ilustra os transportes mais utilizados em algumas cidades médias e permite uma análise comparativa. O uso de automóvel e motocicleta dispara superiormente em relação aos outros tipos, principalmente ao transporte público (ônibus, micro-ônibus), os quais são quase insignificantes.

Os motivos da utilização dos meios de transporte em Londrina, de acordo com dados do Plano Diretor Municipal (PML, 2008), lideram o destino "trabalho" (68,90\%), seguido de "outros" (17,50\%), e também de "escola" (8\%).

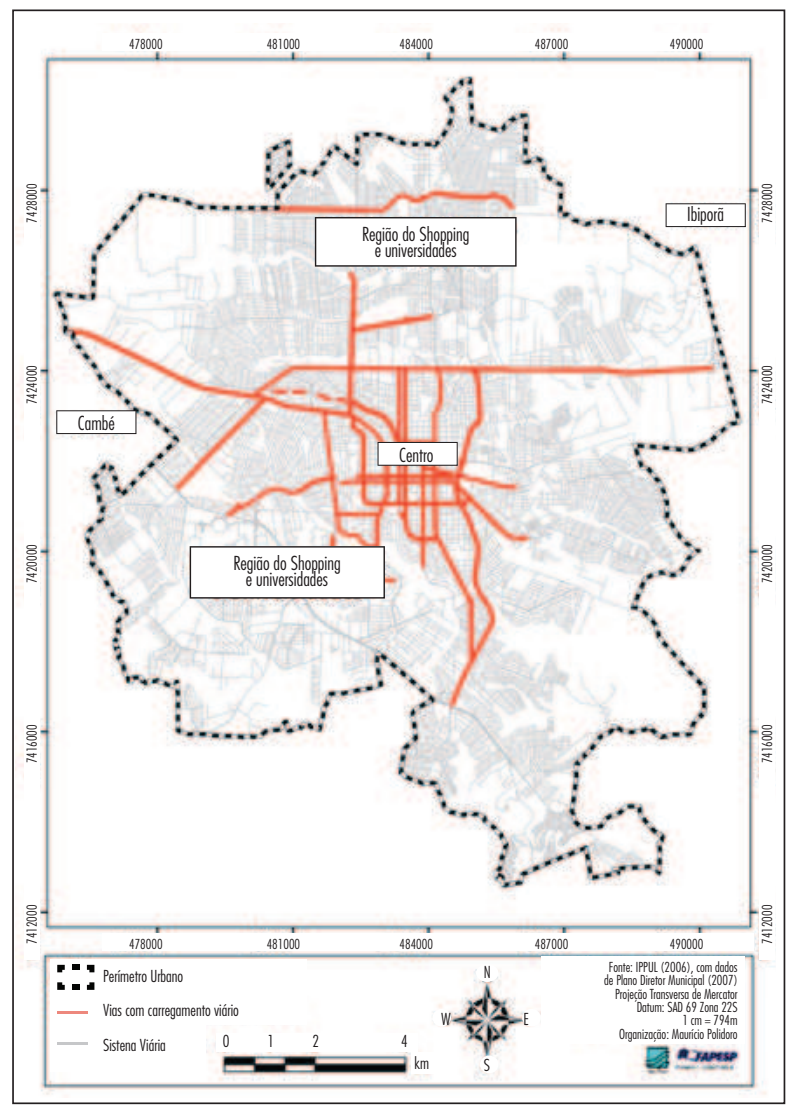

Figura 5 - Entroncamento viário em Londrina Fonte: PML, 2008. 
Segundo informações publicadas no periódico Jornal de Londrina (FERREIRA, 2009) citando IPPUL, em 2006 estimava-se que apenas 7\% dos londrinenses utilizavam a bicicleta como meio de transporte; em municípios como Bauru, o uso da bicicleta e o deslocamento a pé somam $28,2 \%$, e na região metropolitana de São Paulo totalizam 34,4\% (RAIA Jr., 2009).

Em Londrina, no contexto de alg mas cidades médias brasileiras, verifica-se que existe um índice de motorização um pouco menor que o de cidades como Maringá e Ribeirão Preto, mas o índice de bicicletas para cada 100 habitantes também é inferior. 0 número excessivo de automóveis e motos, somado ao reduzido número de bicicletas e de ônibus, trazem duras consequências à qualidade do transporte urbano (Tabela 3).

Neste cenário, o carregamento viário, que afeta cada vez mais a cidade de Londrina, principalmente no horário do pico - que a priori, era das $18 \mathrm{~h}$ às $20 \mathrm{~h}$, mas se estende cada vez mais, conforme depoimentos registrados no Jornal de Londrina (2009) - e afeta os usuários tanto do transporte público, pelo número reduzido de vias preferenciais de escoamento, como os automóveis, bicicletas, pela ausência de ciclovias, e pedestres, que são vítimas de ruas com diversas rotatórias, planejada para o deslocamento por carros.

As vias com maior carregamento (Figura 5) são aquelas que ligam as áreas mais periféricas - por exemplo, os conjuntos habitacionais na região norte e as universidades e shopping na região sul, no sentido região central e vice-versa.

No caso dos conjuntos habitacionais, o deslocamento diário para a região central e circunvizinha, localidade do trabalho da parcela da população e área concentradora dos serviços e comércios gera congestionamentos.

A concentração no shopping center e no sentido das universidades (área mais valorizada da cidade) também provoca entroncamentos viários, assim como em alguns pontos que ligam o município às cidades conurbadas de Cambé e Ibiporã, dada a alta dependência destes em relação ao polarizador.

Diante dessa situação, tem-se observado cada vez mais o esforço de órgãos planejadores, como o IPPUL e a Prefeitura Municipal de Londrina, em parcerias com Banco Internacional de Desenvolvimento (BID), para a construção de novas vias, desapropriação e alargamento de outras, muitas vezes localizadas na região central, em detrimento da implantação de ciclovias em locais onde, de fato, a população possa utilizar para deslocamento diário ou, ainda, de novas linhas de ônibus ou melhoria das existentes, tanto em número quanto em qualidade, inclusive das paradas destes com coberturas satisfatórias, ao contrário da forma precária em que se encontram muitas vezes.

\section{Conclusões}

Observa-se que a cidade tem evoluído para uma constituição cada vez mais complexa, seja pelas dimensões da sua forma ou suas relações sociais. Nesse processo, os ideais do Urbanismo de meados do século XIX de racionalidade dos investimentos públicos e distribuição da infraestrutura e serviços necessários à vida urbana (REIS FILHO, 2006) afastam-se cada vez mais em direção a um futuro incerto.

Tabela 3 - Dados sobre veículos (motorizados e bicicletas)

\begin{tabular}{lcccc}
\hline Município & População* & Automóveis** & Índice de motorização & $\begin{array}{c}\text { Bicicletas } \\
\text { (a cada 100 hab.)** }\end{array}$ \\
\hline Londrina (PR) & 510.707 & 163.904 & 32 & 10 \\
Maringá (PR) & 335.511 & 123.411 & 37 & 11 \\
Ribeirão Preto (SP) & 563.107 & 218.675 & 39 & 14 \\
Bauru (SP) & 359.429 & 119.159 & 33 & 10 \\
Joinville (SC) & 497.331 & 167.568 & 34 & 9 \\
\hline
\end{tabular}

* Fonte: IBGE, 2010.

** Fonte: DENATRAN, 2012. 
Neste processo, no qual a lógica de ocupação do espaço urbano é ditada entre os meandros dos especuladores imobiliários em parceria com o poder público, identifica-se uma expansão desenfreada causando impactos no urbano como espaço de vivência.

Notam-se, cada vez mais, grupos sociais dirigindo-se para os limites do perímetro urbano, seja em busca de oportunidades de trabalho nas indústrias e moradias mais baratas, ou aqueles mais abastados que desejam um novo estilo de vida, longe do caos urbano, porém com práticas espaciais diferenciadas e acesso desigual aos recursos.

Isto não apenas delineia uma cidade desigual do ponto de vista urbanístico, mas também nas relações sociais, conforme podemos observar nos apontamentos de Carlos (2007, p. 188):

[...] o momento atual sinaliza uma profunda crise social pressentida pela deterioração das relações sociais, pela tendência ao escasseamento das relações de vizinhança, pela diminuição dos espaços de sociabilidade (aquele da rua, aquele do pequeno comércio de bairro, das praças), pela implosão do bairro, pela deterioração do espaço público, pelo esvaziamento.

O afastamento da área consolidada leva a novas formas de relacionamentos sociais e, considerando estes relacionamentos como principais agentes produtores do espaço urbano, costumes que têm impactado a vida da população em sua totalidade.

0 uso indiscriminado do automóvel, por exemplo, tem se firmado como uma das exigências desse novo estilo de vida, já que o deslocamento por longas distâncias a fim de obter serviços como escola, saúde, lazer e trabalho exigem meios mais rápidos $\mathrm{e}$ confortáveis de locomoção.

Com a influência de políticas e marketing que induzem ao uso do carro, a população tem optado, quando possível, pela aquisição desse meio de transporte. Na contramão deste evento, estão os investimentos no transporte público e caminhos acessíveis aos pedestres que são renegados pela cidade, cada vez mais especializada e concentradora de atividades.

Essa dialética de expansão urbana em Londrina tem guiado a cidade para o uso exclusivo de automóvel. A combinação da concentração de serviços apenas na área central e em pontos periféricos específicos, da densidade demográfica desigual aliada à falta de estratégias de planejamento adequadas e da opção do automóvel como o principal meio de deslocamento, cria pontos de congestionamento que paralisam a mobilidade da população, inclusive daquelas pessoas que utilizam o transporte público.

Como resultado, tem-se observado nos últimos anos o esforço do Poder Público Municipal em expandir as vias por meio de projetos milionários de alargamento que envolvem desapropriações de imóveis na região central ou construção de pontes que deixam o pedestre cada vez mais à margem do espaço urbano.

Esse processo, em constante movimento na cidade de Londrina e em muitas outras cidades médias brasileiras, deve ser controlado enquanto ainda há tempo. À medida que a urbanização desenfreada vai para além dos limites político-administrativos (como já consolidado em diversas áreas metropolitanas do Brasil e no mundo), novos direcionamentos de planejamento urbano e de políticas devem ser traçados.

E tratando-se de planejamento no Brasil, vale salientar que os projetos e planos a serem traçados devem vencer a temporalidade política e atingir os objetivos esquematizados pela soberania popular para daí, então, buscar-se o desenvolvimento urbano, entendido aqui como um princípio articulado entre justiça social, qualidade de vida e ecologia, mas principalmente inclusivo.

\section{Agradecimentos}

Os autores agradecem à Fundação de Amparo à Pesquisa do Estado de São Paulo pelo apoio ao projeto "Impactos Ambientais Urbanos em Áreas de Expansão: Desafios ao Planejamento Metropolitano", por meio do processo n. 2009/11086-8. Agradecemos também ao CNPq pelo apoio ao Projeto n. 06278, "Atlas Digital da Região Metropolitana de Londrina - PR - Brasil”.

\section{Referências}

AURAND, A. G. Is smarth growth for low-income households: a study of the impact of four smarth growth principles on the supply of affordable housing. $451 \mathrm{f}$. Thesis (Doctorate in Philosophy) - University of Pittsburgh, Pittsburgh, 2007. 
BURCHELL, R. The costs of sprawl: revisited. Transportation Cooperative Research Program. Report n. 39. Washington, DC: National Academy Press, 1998.

BURCHELL, R.; MUKHJERJI, S. Conventional development versus managed growth: the costs of sprawl. American Journal of Public Health, v. 93, n. 9, p. 1534-1540, set. 2003.

CARBONELL, A.; YARO, R. American spatial development and the new megalopolis. Land Lines, v. 17, n. 2, abr. 2005.

CARLOS, A. F. A. Metamorfoses urbanas. GeoTextos, v. 3, n. 1/2, p. 187-200, 2007.

CASARIL, C. C. A expansão físico-territorial da cidade de Londrina e seu processo de verticalização: 1950-2000. Revista Geografia (Londrina), v. 18, p. 65-94, jan./jun. 2009.

CHOAY, F. O reino do urbano e a morte da cidade. Projeto História, São Paulo, n. 18, p. 67-89, maio 1999.

DEPARTAMENTO NACIONAL DE TRÂNSITO - DENATRAN. Frota de veículos. Frotas dos anos de 1998, 1999, 2000, 2001, 2002, 2003, 2004, 2005, 2011. 2012. Disponível em: <http://www.denatran.gov.br/frota.htm>. Acesso em: 5 mar. 2012

FERREIRA, M. Gargalos do trânsito de Londrina. Trânsito. Jornal de Londrina, 13 set. 2009. Disponível em: <http://www.jornaldelondrina.com.br/online/conteudo.phtml?tl=1\&id=923437\&tit=Preferencia-por-carro-deixa-Na>. Acesso em: 14 set. 2009.

INSTITUTO BRASILEIRO DE GEOGRAFIA E ESTATÍSTICA - IBGE. Censo demográfico: série histórica. 2010. Disponível em: <http://www.sidra.ibge.gov.br/bda/po-

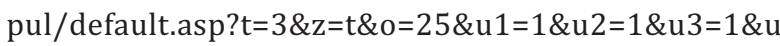
4=1\&u5=1\&u6=1>. Acesso em: 15 jun. 2010.

JOHNSON, M. P. Environmental impacts of urban sprawl: a survey of the literature and proposed research agenda. Environmentand Planning A., v. 33, p. 717-735, 2001.

JONG, H. de; ROUWETTE, A. Cycling-incluse policy development: a handbook. Alemanha: GTZ, 2009. Disponível em: <www.gtz.de/en/themen/28407.htm>. Acesso em: 21 abr. 2010.

LIMONAD, E. Urbanização dispersa: mais uma forma de expressão urbana? Revista Formação, v. 1, n. 14, p. 3145, jan./jun. 2007.
LISBOA, C. K.; BARROS, M. V. F. A pegada ecológica como instrumento de avaliação ambiental para a cidade de Londrina. Confins, n. 8, mar. 2010. Disponível em: <http://confins.revues.org/index6395.html>. Acesso em: 21 maio 2010.

MORRIS, D. E. It's a sprawl world after all: the human cost of unplanned growth - and visions of a better future. Gabriola: New Society Publishers, 2005.

OJIMA, R.; HOGAN, D. J. População, urbanização e ambiente no cenário das mudanças ambientais globais: debates e desafios para a demografia brasileira. In: ENCONTRO NACIONAL DE ESTUDOS POPULACIONAIS, 16., 2008, Caxambu. Anais... Caxambu: ABEP, 2008a.

OJIMA, R.; HOGAN, D. J. Crescimento urbano e peri-urbanização: redistribuição espacial da população em novas fronteiras da mudança ambiental. In: ENCONTRO DA ASSOCIAÇÃO NACIONAL DE PÓS-GRADUAÇÃO E PESQUISA EM AMBIENTE E SOCIEDADE, 4., 2008, Brasília. Anais... Brasília: ANPPAS, 2008b.

PASSOS, V. R. L. A verticalização de Londrina: 1970/2000. 2007. 203 f. Dissertação (Mestrado em Geografia, Meio Ambiente e Desenvolvimento) Universidade Estadual de Londrina, Londrina, 2007.

POLIDORO, M. Sprawl urbano em Londrina: desafio ao planejamento urbano. 2010. 76 f. Monografia (Especialização em Análise e Educação Ambiental em Ciências da Terra) - Universidade Estadual de Londrina, Londrina, 2010.

PREFEITURA MUNICIPAL DE LONDRINA - PML. Plano Diretor Municipal de Londrina. Londrina: PML, 2008. Disponível em: <http://home.londrina.pr.gov.br/homenovo.php?opcao=home\&item =plano_diretor $>$. Acesso em: 10 mar. 2010.

RAIA Jr., A. A. Transporte para cidades sustentáveis. In: SIMPÓSIO DE PÓS-GRADUAÇÃO EM ENGENHARIA URBANA, 2., 2009, Maringá. Anais... Maringá: UEM, 2009.

RAZENTE, N. Ocupação do espaço urbano de Londrina. 1983. 393 f. Dissertação (Mestrado em Arquitetura e Urbanismo) - Universidade Federal de Pernambuco, Recife, 1983.

REIS FILHO, N. G. Notas sobre urbanização dispersa e novas formas de tecido urbano. São Paulo: Via das Artes, 2006. 
RIBEIRO, E. L.; SILVEIRA, J. A. R. O fenômeno do sprawling urbano. AU - Arquitetura e Urbanismo, ano 24, n. 185, p. 74-78, 2009. Disponível em: <http://www.revistaau. com.br/arquitetura-urbanismo/185/imprime149628. asp>. Acesso em: 10 mar. 2010.

RIBEIRO, W. da S. A formação do Centro Principal de Londrina e o estudo da centralidade urbana. Revista Geografia (Londrina), Londrina, v. 12, n. 2, p. 20-46, 2004.
TOMAZZI, N. D. Norte do Paraná: histórias e fantasmagorias. Curitiba: Aos Quatro Ventos, 2000.

Recebido: 23/02/2012

Received: 02/23/2012

Aprovado: $27 / 03 / 2012$

Approved: 03/27/ 2012 